\title{
Jubilee of the City and Guilds (Engineering) College, London
}

$\mathrm{O}^{\mathrm{N}}$ Monday next, February 4, the City and Guilds College, affectionately known to many besides its students as the 'Central', is to celebrate the jubilee of its foundation, the present building having been opened in 1884. It is too near the achievement for us properly to assess the value of the work done in founding and establishing London's and the Empire's premier school of engineering, but it is more than probable that a century hence the historian will regard the movement which led to the establishment of the colleges at Finsbury and South Kensington as outstanding in importance and in the results it produced.

From the first, the 'Central' has been characterised by its originality and independence; never were four colleagues so outstanding in this respect as its original professors, Armstrong and Ayrton promoted from Finsbury a year after the establishment of their new building there, Unwin from Coopers Hill and Henrici from University College, London. In principle they were in agreement, and each knew they had problems to solve; but each set to work to develop his own department to the best of his ability, and the College developed on these individual lines though also as a whole, and became great perhaps as a consequence.

A strong effort was made to make the chemistry course a part of the curriculum of the engineer and to insist on the chemist passing through a comprehensive course in mathematics, physics and the elements of engineering. It proved, however, that as a whole the engineers did not want to learn chemistry, chiefly perhaps because the subject never appealed to their mentality, since the tendency of the engineer is to construct and not to think or seek hidden meanings. It is of significance in this connexion that scarcely half a dozen of the Centralian engineers have distinguished themselves in chemical engineering, whereas the Centralian chemists, owing in part to their engineering training, have been uniformly successful as pioneers in developing the newer industries. It is still a fact that chemists have to learn engineering and become chemical engineers in order to take part in the enormous developments in chemical industry, and the lack of such trained engineers in Britain as compared with their super. abundance in Germany and America has been definitely a handicap.

There is no need to record here how the College has passed from success to success; after the first few years, it was always full with students carefully selected by an entrance examination which grew increasingly exacting. The rapidly developing electrical industry was manned each year by new batches of Centralians imbued with Ayrton's zeal and enthusiasm, and civil and mechanical engineering positions at home and abroad were increasingly filled by Centralians loyal to the Unwin thoroughness. Time, alas, brought changes in the professoriate; Mather succeeded Ayrton, Klugh followed Henrici, Dalby came from Finsbury on Unwin's retirement, whilst the Chemical Department was closed when the 'Central' was merged with the Imperial College of Science and Technology, leading to the retirement of Armstrong, who is the only survivor of the four great original founders.

So far, the early development of the College has been emphasised and the birth of its traditions, which few will be unwise enough to minimise. For the new student tradition must mean much; it is up to him to be worthy of it : as Kipling says, "Of one muster all of us, .. . keen in his vocation" ; whilst, in consequence of the tradition to produce highly trained, reflective, inventive graduates, employers have sought to obtain the 'Central' men as they graduated.

Perhaps the first break in the old order came with the inclusion of the 'Central' as a school of the University of London in the Faculty of Engineering in 1899 and the attachment of the University examination and degree in engineering to the diploma of A.C.G.I.

To-day the City and Guilds College has its own governing committee, or delegacy, within the organisation of the Imperial College. Its courses are essentially engineering ; the number of departments has expanded. There is more specialism, and a number of eminent and devoted professors are giving of their best to training the men so urgently needed for Britain to hold its own in the intense struggle for industrial supremacy. In some ways the requirements are other, more specialised than fifty years ago; in other ways, the need is still the same for men of broad out. look, trained to think and create rather than to memorise and to imitate. The influence of the great teacher, of the man of genius, independence and vigour, is still as great on the student in his most impressionable age, and the College will be wise to select and retain such, be they young or old, whatever may be the cost. Countless biographies of successful men testify to this influence of their teachers on them, prevailing throughout their lives.

The 'Central' has done a great work; it has been well and unselfishly served in the past; it will do so much in the future.

E. F. A. 